\title{
Sacral Hiatus Study in Dry Human Sacra
}

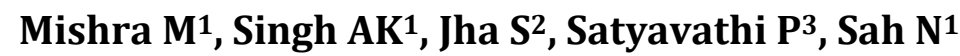 \\ Department of Anatomy \\ Pratima Institute of Medical Sciences, Karimnagar, Andhra Pradesh, India
}

1Department of Anatomy, Janaki Medical College, Janakpur, Nepal
${ }^{2}$ Department of Physiology, Janaki Medical College, Janakpur, Nepal
${ }^{3}$ Department of Anatomy, Pratima Institute of Medical Sciences, Karimnagar, Andhra Pradesh, India

Department of Anatomy, Pratima Institute of Medical Sciences, Karimnagar, And ra Pradesh, India

\begin{abstract}
Background and objectives: The sacral hiatus is the site for caudal epidural anaesthesia during perineal surgery and also for a painless delivery. It is also used for three dimensional colour visualization of lumbosacral epidural space in orthopaedic practice for diagnosis and treatment. Work on the morphometrical study of the sacral hiatus is limited, especially in south indian population. So this study is carried to examine, measure and record the morphometry of sacral hiatus in order to study the anatomical variations which will be useful for caudal epidural anaesthesia.

Material and Methods: The study was conducted in the Department of Anatomy, Prathima Institute of Medical Science, Naganur, Andhra Pradesh. 93 dry sacra with complete sacral hiatus were taken for the study.. The shape of the sacral hiatus was noted by naked eye. Level of the apex and base of the sacral hiatus was noted with respect to the sacral vertebra. The length of sacral hiatus was measured from apex to the midpoint of base, the anteroposterior depth of sacral hiatus at the apex was measured with the help of vernier calipers. The transverse width of sacral hiatus at the base was measured between the inner aspects of inferior limit of the sacral cornu with the help of divider and then adjusted, and calculated with vernier caliper.
\end{abstract}

Results: In 47 (50.53 \%) sacra the shape was Inverted-U and in 25 (26.9\%) sacra Inverted-V. The irregular shaped of sacral hiatus was observed in 11 (11.8\%) cases. A "Dumbbell" shaped sacral hiatus was observed in $5(5.4 \%)$ cases with a nodular bony growth projecting medially from both margins . The dorsal wall of sacral canal was entirely absence in $4(4.3 \%)$ cases . Absence of sacral hiatus, a rare phenomenon, was observed in $1(1 \%)$ specimens only.

Conclusion: In the present study, elongated hiatus and narrowing of the sacral canal at apex of sacral hiatus was found in a significant percentage, which should be kept in mind while giving the caudal anaesthesia in Andhra Pradesh region.

Key words: apex, base, caudal epidural anaesthesia, sacral hiatus. 


\section{INRODUCTION}

The Sacrum is a large triangular bone formed by the fusion of five sacral vertebrae and forms the caudal end of the vertebral column. It forms posterosuperior wall of the pelvic cavity wedged between the two innominate bones. Its dorsal surface present an arch shaped gap at the caudal end called as the sacral hiatus [1].

Sacrum is one of the bones which exhibit variations [2]. The opening at the caudal end of sacral canal is known as sacral hiatus. It is formed due to the failure of fusion of laminae of the fifth (occasionally 4th) sacral vertebra. The sacral hiatus transmits the fifth sacral nerve and coccygeal nerves [1]. The dural sac ends at the level of second sacral vertebra above the sacral hiatus. Therefore it forms a convenient region for caudal epidural anaesthesia of structures innervated by these nerves.

The sacral hiatus is the site for caudal epidural anesthesia during perineal surgery and also for a painless delivery. It is also used for three dimensional color visualization of lumbosacral epidural space in orthopaedic practice for diagnosis and treatment.

Work on the morphometrical study of the sacral hiatus is limited, especially in south indian population. The present study was undertaken to find out the anatomical variations of sacral hiatus of the cadaver of south Indian population in and around Karimnagar and is expected to help in filling this deficiency at least to a certain extent.

\section{MATERIALS AND METHODS}

This is a Cross-sectional study carried out on 93 dry human sacra in Andra pradesh to study the anatomical variations of sacral hiatus.
The study was conducted in the Department of Anatomy, Prathima Institute of Medical Science, Naganur, Karimnagar, Andhra Pradesh. 93 human sacra were collected from Department of Anatomy, Prathima Institute of Medical Science, Naganur, Karimnagar. Only dry sacra with complete sacral hiatus were taken for the study. Damaged sacra were excluded for the study. Various parameters were studied and measured. The shape of the sacral hiatus was noted by naked eye. Level of the apex and base of the sacral hiatus was noted with respect to the sacral vertebra. The length of sacral hiatus was measured from apex to the midpoint of base, the anteroposterior depth of sacral hiatus at the apex was measured with the help of vernier calipers. The transverse width of sacral hiatus at the base was measured between the inner aspects of inferior limit of the sacral cornu with the help of divider and then adjusted, and calculated with vernier caliper. The data were entered in SPSS version 15.0 and was used for the analysis and presentation of data.

\section{RESULTS}

All the sacrum studied were composed of five segments in $93(100 \%)$ cases. There were many variations in the shape of sacral hiatus and is shown in table 1.

Table 1: Shape of sacral hiatus

\begin{tabular}{|c|l|c|c|}
\hline SN & \multicolumn{1}{|c|}{ Shape } & Number & $\mathbf{\%}$ \\
\hline 1 & Inverted- U & 47 & 50.53 \\
\hline 2 & Inverted- V & 25 & 26.9 \\
\hline 3 & Irregular & 11 & 11.80 \\
\hline 4 & Dumbbell & 5 & 5.4 \\
\hline 5 & $\begin{array}{l}\text { Absence of } \\
\text { dorsal wall }\end{array}$ & 4 & 4.3 \\
\hline 6 & $\begin{array}{l}\text { Absence of sacral } \\
\text { hiatus }\end{array}$ & 1 & 1.07 \\
\hline \multicolumn{2}{|c|}{ Total } & 93 & 100 \\
\hline
\end{tabular}


In $47(50.53 \%)$ sacra the shape was Inverted-U and in 25 (26.9\%) sacra Inverted$\mathrm{V}$. Both the above types were considered as normal and the sacral hiatus was present against $4^{\text {th }}$ and $5^{\text {th }}$ sacral segments. The irregular shaped of sacral hiatus was observed in 11 (11.8\%) cases. A "Dumbbell" shaped sacral hiatus was observed in 5 (5.4\%) cases with a nodular bony growth projecting medially from both margins. The dorsal wall of sacral canal was entirely absence in 4 (4.3\%) cases. Absence of sacral hiatus, a rare phenomenon, was observed in 1 (1\%) specimens only.

The level of the apex of SH and that of base was quite variable (table 2 and 3 ). The level of the apex of SH extended between middle of $3^{\text {rd }}$ to middle of $5^{\text {th }}$ sacral segments (table 2 ).

Table 2: Level of Apex of Sacral hiatus with respect to level of sacral vertebra

\begin{tabular}{|l|l|c|c|}
\hline SN & Level of Apex & Number & \% \\
\hline 1 & $5^{\text {th }}$ Sacral Vertebra & 3 & 3.40 \\
\hline 2 & $4^{\text {th }}$ Sacral Vertebra & 49 & 55.70 \\
\hline 3 & $3^{\text {rd }}$ Sacral Vertebra & 36 & 40.90 \\
\hline \multicolumn{2}{|c|}{ Total } & 88 & 100 \\
\hline
\end{tabular}

Table-03: Level of Base of Sacral hiatus with respect to level of sacral vertebra

\begin{tabular}{|c|c|c|c|}
\hline SN & Level of Base & Number & $\begin{array}{c}\text { Percentage } \\
\%\end{array}$ \\
\hline 1 & $\begin{array}{l}5^{\text {th }} \text { Sacral } \\
\text { Vertebra }\end{array}$ & 79 & 89.77 \\
\hline 2 & $\begin{array}{l}4^{\text {th }} \text { Sacral } \\
\text { Vertebra }\end{array}$ & 3 & 3.42 \\
\hline 3 & $\begin{array}{l}1^{\text {st }} \text { coccyx } \\
\text { vertebra }\end{array}$ & 6 & 6.81 \\
\hline \multicolumn{2}{|c|}{ Total } & 88 & $100 \%$ \\
\hline
\end{tabular}

The anteroposterior depth of sacral canal at the apex ranged between $2 \mathrm{~mm}$ to $9 \mathrm{~mm}$ (Table.No.6 \& 9 ).
Table 4: Length of Sacral hiatus from apex to midpoint of base

\begin{tabular}{|c|c|c|c|}
\hline SN & $\begin{array}{c}\text { Length of } \\
\text { sacral hiatus } \\
\mathbf{( m m )}\end{array}$ & $\begin{array}{c}\text { Number } \\
\mathbf{( n = 8 8 )}\end{array}$ & $\begin{array}{c}\text { Percentage } \\
\mathbf{\%}\end{array}$ \\
\hline 1 & $0-10$ & 8 & 9.09 \\
\hline 2 & $11-20$ & 39 & 44.31 \\
\hline 3 & $21-30$ & 27 & 30.70 \\
\hline 4 & $31-40$ & 13 & 14.77 \\
\hline 5 & $41-50$ & 1 & 1.13 \\
\hline
\end{tabular}

Table 5 : Transverse width of sacral hiatus at the base measured between the inner aspect of inferior limit of sacral cornua

\begin{tabular}{|l|c|c|c|}
\hline SN & $\begin{array}{c}\text { Transverse } \\
\text { width (mm) }\end{array}$ & $\begin{array}{c}\text { Number } \\
\text { (n=88) }\end{array}$ & $\begin{array}{c}\text { Percentage } \\
\text { (\%) }\end{array}$ \\
\hline 1 & $0-5$ & 1 & 1.14 \\
\hline 2 & $6-10$ & 18 & 20.46 \\
\hline 3 & $11-15$ & 51 & 57.95 \\
\hline 4 & $16-20$ & 18 & 20.45 \\
\hline
\end{tabular}

Table 6: Anteroposterior depth of sacral canal at the level of apex

\begin{tabular}{|l|c|c|c|}
\hline SN & $\begin{array}{c}\text { AP depth } \\
\text { (mm) }\end{array}$ & $\begin{array}{c}\text { Number } \\
(\mathbf{n = 8 8})\end{array}$ & $\begin{array}{c}\text { Percentage } \\
\mathbf{\%}\end{array}$ \\
\hline 1 & $0-3$ & 21 & 23.86 \\
\hline 2 & $4-6$ & 56 & 63.63 \\
\hline 3 & $7-9$ & 11 & 12.51 \\
\hline
\end{tabular}

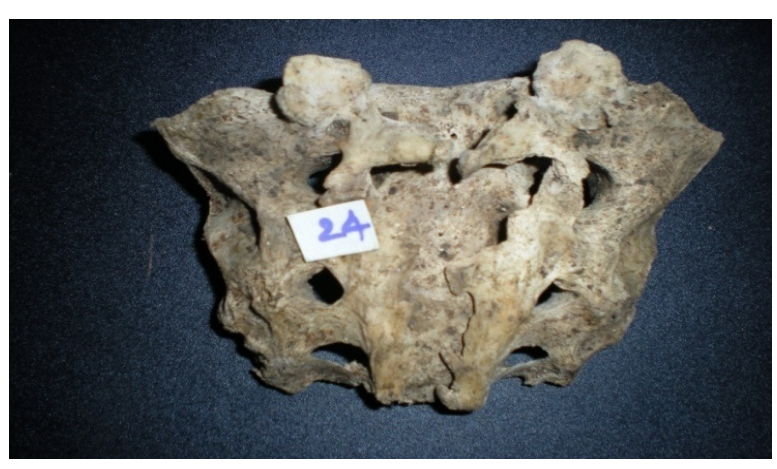

Fig no. 1: Absence of dorsal wall of sacrum 


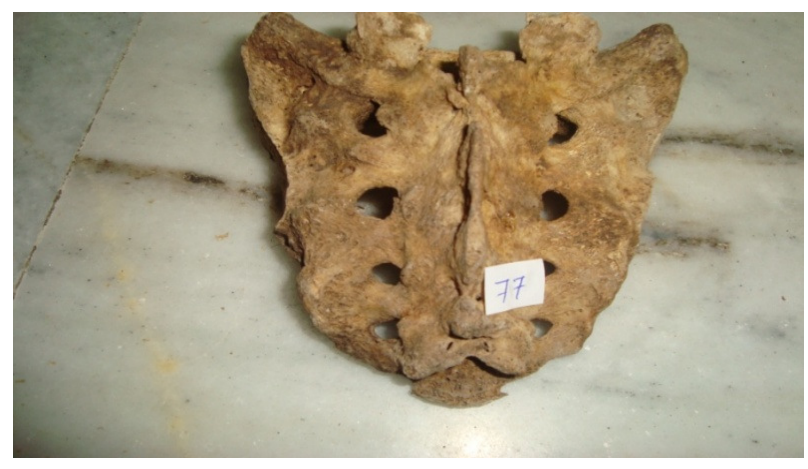

Fig no.2: Absence of sacral Hiatus

\section{DISCUSSION}

The detailed morphometric study of sacral hiatus is of great relevance, since this route is frequently utilized for caudal epidural anaesthesia in perineal surgery and caudal analgesia for a painless delivery. Edward and Hingson in 1941, for the first time took the advantage of this natural gap at the lower end of sacral canal for continuous caudal analgesia during labour [3]. Sacral hiatus has a somewhat triangular outline when seen from the dorsal aspect [4]. The level of the apex of sacral hiatus lies at the lower third of the body of $4^{\text {th }}$ sacral vertebra and sacral hiatus is the place where caudal epidural anaesthesia is given for the operations on sacral dermatomes.

In the present study the shapes of sacral hiatus were mostly inverted-U shaped (51.6\%) and inverted-V (25.8\%). Both the above types were considered as normal. In 5 (5.4\%), its outline was like a Dumb-bell which was very low when compared to previous workers. Nagar (2004)-reported dumb-bell shape in $13.3 \%$ [4] and Kumar et al (1992) reported such cases in $7.43 \%$ cases [5]. Bifid sacral hiatus was seen in 4 sacra (2\%) in our study which was similar to that reported by other study [4]. It was in about $1.5 \%$ cases. There were several studies in which there is reported cases of complete agenesis of sacral hiatus. Trotter et al reported agenesis in 1.8\% [6], Vinod kumar et al [5] in 3 sacra (1.49\%) and Nagar in 4 sacra (1.5\%)[4] . Kiran. V. et al found 1 sacrum as agenesis of sacral hiatus due to absence of dorsal wall of sacral canal out of 50 sacra(2\%)[7]. Suma H Y studied 150 sacra, out of that inverted -U(44\%), inverted$\mathrm{V}(28.27 \%), \quad$ irregular $\quad(10.1 \%)$, dumbbell(12.3\%) and complete spina bifida(5.33\%). The apex of the sacral hiatus was found at the level of $4^{\text {th }}$ sacrl vertebra( $77.5 \%)$ and base of the sacral hiatus was found at the level of S5(64.38\%)[8]. In the present study complete agenesis was found in $4(5.4 \%)$ and absence of sacral hiatus due to bony over growth, a rare phenomenon was observed in single sacrum (1.07\%) which was similar in other two study; in $2(0.7 \%)$ sacra [4] and in $0.9 \%$ [5]. But in a study conducted by Sekiguchi et al, sacral hiatus was absent in 3\% cases which was higher [9]. Nagar SK also noted various shapes of sacral hiatus most common being inverted-U in 112 $(41.5 \%)$ sacra and inverted-V in 73sacra (27\%) [5]. Vinod kumar et al also noted various shapes of sacral hiatus, most common being inverted-V in $94 \quad(46.53 \%)$ and inverted-U in 60 (29.70\%) [5].

Susan Strandring et al states that the apex of sacral hiatus is present at the level of $4^{\text {th }}$ sacral vertebra [1]. In the present study the apex of sacral hiatus was seen most commonly at the level of 4 th sacral vertebra in 49sacra (55.70\%), which was almost similar [4], higher [5, 8 . Earlier studies by Trotter et al and Lanier et al in their series have reported the mean level of apex of sacral hiatus to be at lower third of 4th sacral vertebra $[6,10]$.

Most of the studies including the present study noted that location of apex can vary from upper part of second sacral vertebra to lower part of fifth sacral vertebra. Base of the 
sacral hiatus was seen at the level of fifth sacral vertebra in $89.77 \%$ in the present study, which was higher when compared to study conducted by Kumar et al [5], (83.17\%) and also when compared to Nagar SK [4]. 191sacra (72.6\%) at the level of fifth sacral vertebra out of 270 bones studied.

Length of sacral hiatus varied from $4 \mathrm{~mm}$ to $42 \mathrm{~mm}$ and the arithmetic mean was $19.73 \mathrm{~mm}$ and median was $\mathbf{1 9 . 0 0 m m}$ and reference range was between 6.68 to $38.62 \mathrm{~mm}$ in the present study. This is similar to that reported by earlier workers [5] who observed mean length of sacral hiatus as $20 \mathrm{~mm}$ in males and $18.9 \mathrm{~mm}$ in females among north Indians. Sacral hiatus length in American males and females was found to be $24.8 \mathrm{~mm}$ and $19.8 \mathrm{~mm}$ respectively [6]. Similar results were noted by Lanier et al noted mean length being $25.3 \mathrm{~mm}$ [10].

Anteroposterior depth of sacral canal at apex of sacral hiatus is important as it should be sufficiently large to admit a needle. Various diameters lead to subcutaneous deposition of anaesthetic drug. In the present study the anteroposterior depth ranged from 2 to $9 \mathrm{~mm}$ with arithmetic mean of $4.0 \mathrm{~mm}$ and median of $4.0 \mathrm{~mm}$. This report is similar and comparable to the finding of other scholar [3, $5,9,10]$.

In the present study, sacra having anteroposterior depth of sacral canal at apex of sacral hiatus less than $3 \mathrm{~mm}$ was observed in $21(23.86 \%)$ cases which is higher than the earlier studies [6] Nagar SK noted in 4 sacra $(15.6 \%)$ with $0-3 \mathrm{~mm}$ depth, while Lanier et al (1944) noted no cases with depth less than $3 \mathrm{~mm}[4,10]$. In present study anteroposterior depth of sacral canal at apex of sacral hiatus ranges between $4 \mathrm{~mm}-6 \mathrm{~mm}$ in 56 bones(63.63\%) which was similar to previous study in Indian population [4].
Arithmetic mean was $4.0 \mathrm{~mm}$ in the present study, which was similar to the study conducted by Kumar et al as $4.8 \mathrm{~mm}$ [5].

In the present study the transverse width varied from 4 to $18 \mathrm{~mm}$, having arithmetic mean of $12.11 \mathrm{~mm}$, median $\mathbf{1 1 . 8 4 m m}$ and reference range between $5.38 \mathrm{~mm}$ to $17.45 \mathrm{~mm}$. In more than half $57.95 \%$ cases transverse width of sacral hiatus at base was from $11 \mathrm{~mm}-15 \mathrm{~mm}$ and in $78.4 \%$ cases transverse width was from $6 \mathrm{~mm}-15 \mathrm{~mm}$ which was almost similar to the next study conducted in india [4] which ranges from $3 \mathrm{~mm}-19 \mathrm{~mm}$ and in more than half $54 \%$ cases it was $10 \mathrm{~mm}-15 \mathrm{~mm}$ and in $84 \%$ cases it was from $6 \mathrm{~mm}-15 \mathrm{~mm}$. The transverse width was higher among Americans compared to present study. It varies from $7 \mathrm{~mm}-26 \mathrm{~mm}$ with arithmetic mean of $17 \mathrm{~mm}$ among Americans [6]. Lanier et al also reported bigger transverse width at base to be $19.3 \mathrm{~mm}$ than to the present study [10]. Sekiguchi $M$ et al have reported a lower arithmetic mean of transverse width to be $10.2 \mathrm{~mm}$ among [9].

\section{CONCLUSIONS}

The percentage of absent of sacral hiatus due to fusion of sacral cornua is $1.07 \%$ and non formation of sacral hiatus due to absent dorsal wall of sacral canal is $5.40 \%$. In both the above condition the epidural anesthesia will be failure (upto7\%). If there is a doubt about these to variation then MRI/ Floroscopy should be done to visualize them, before taking of the procedure of the epidural anesthesia. There are anatomical variations in the sacral hiatus, which may relate to the complication to caudal epidural anesthesia. Understanding of these variations may improve the success rate of caudal epidural anesthesia in this part of population. 


\section{ACKNOWLEDGEMENT}

Authors wish to acknowledge the support of Assoc. Prof. Kshitiz Upadhyay-Dhungel, department of Physiology, JMC, Janakpur for his support in preparation of manuscript.

\section{REFERENCES}

1. Standring S. Grays Anatomy, 39th Ed, Elsevier Churchill Livingstone, London, 2005; P: 749 754.

2. Esses SE, Botsford DJ: Surgical Anatomy and Operative Approaches to the Sacrum, In Frymoyer JW, Ducker TB, Hadler NM et al (eds): The Adult Spine. Principals and Practice, 2nd Ed. Philadelphia: Lippincott-Raven, 1997; 2:2329 - 2341 .

3. Edwards WB, Hingson RA. Continuous caudal anaesthesia in obstetrics. American journal of surgery 1942; 57: 459 - 464.

4. Nagar SK. A study of sacral hiatus in dry human sacra. Journal of Anatomical Society of India 2004; 53(2): 18 - 21.

5. Kumar V et al. Morphometrical study of sacral hiatus. Journal of Anatomical society of India 1992; 41(1): $7-13$.

6. Trotter M. and Letterman GS. Variations of the female sacrum: Their significance in continuous caudal anaesthesia. Surg. Gynecol. Obstet 1944; 78(4): 419 - 424.

7. Kiran V et al. Agenesis of dorsal wall of sacral canal. Anatomica karnatka 2011; 5 (1): 69-71.

8. Suma HY et al. A study of sacral hiatus among sacra in south Indian population. Anatomica karnatka 2011; 5 (3): 40-44.

9. Sekiguchi M, Yabuki S, Satoh K, Kikuchi S. An Anatomical Study of the Sacral Hiatus: A Basis for Successful Caudal Epidural Block. Clinical journal of Pain 2004; 20(1): 51 - 54.

10. Lanier VS, Mcknight HE, Trotter M. Caudal analgesia: An experimental and anatomical study. American journal of Obstetrics and Gynaecology 1944; 47(5): 633 - 641. 